\title{
Cutaneous Mature T-Cell and NK-Cell Neoplasm
}

National Cancer Institute

\section{Source}

National Cancer Institute. Cutaneous Mature T-Cell and NK-Cell Neoplasm. NCI

Thesaurus. Code 145250

A group of neoplasms composed of T-lymphocytes with a mature (peripheral/post-

thymic) immunophenotypic profile and/or NK-cells affecting the skin. 